\author{
CSID Working Paper Series
}

\#CSID-2012-007

\title{
Environmental variability and collective action: Experimental insights from an irrigation game
}

\author{
John M. Anderies \\ Arizona State University, USA \\ Marco A. Janssen \\ Center for the Study of Institutional Diversity, School of Human Evolution and Social Change, Arizona State University, \\ Tempe, AZ 85287-2402, USA \\ Allen Lee \\ Center for the Study of Institutional Diversity, School of Human Evolution and Social Change, Arizona State University, \\ Tempe, AZ 85287-2402, USA \\ Hannah Wasserman \\ Department of Economics, W.P. Carey School of Business, Arizona State University, Tempe, AZ 85287-9801 \\ June 20, 2012 \\ The Center for the Study of Institutional Diversity resides in the School of Human Evolution and Social Change at \\ Arizona State University. CSID can be found on the internet at: http://csid.asu.edu. CSID can be reached via email at \\ csid@asu.edu.
}




\title{
Environmental variability and collective action: Experimental insights from an irrigation game
}

\author{
John M. Anderies ${ }^{a}$, Marco A. Janssen ${ }^{b}$, Allen Lee $^{c}$, Hannah Wasserman ${ }^{d}$
}

${ }^{a}$ Center for the Study of Institutional Diversity, School of Human Evolution and Social Change, Arizona State University, Tempe, AZ 85287-2402, USA;

${ }^{b}$ Center for the Study of Institutional Diversity, School of Human Evolution and Social Change, Arizona State University, Tempe, AZ 85287-2402, USA;

${ }^{c}$ Center for the Study of Institutional Diversity, School of Human Evolution and Social Change, Arizona State University, Tempe, AZ 85287-2402, USA;

${ }^{d}$ Department of Economics, W.P. Carey School of Business, Arizona State University, Tempe, AZ 85287-9801;

Corresponding author:

John M. Anderies

School of Human Evolution and Social Change

School of Sustainability

Arizona State University

PO Box 87402

Tempe, AZ 85287-2402, USA

m.anderies@asu.edu

\begin{abstract}
:
Studies of collective action in commons dilemmas in social-ecological systems typically focus on scenarios in which actors all share symmetric (or similar) positions in relation to the common-pool resource. Many common social-ecological systems do not meet these criteria, most notably, irrigation systems. Participants in irrigation systems must solve two related collective action problems: 1) the provisioning of physical infrastructure necessary to utilize the resource (water), and 2) the asymmetric common-pool resource dilemma where the relative positions of head-enders and tail-enders generate asymmetric access to the resource itself (water). In times of scarcity, head-enders have an incentive to not share water with tail-enders. Likewise, tail-enders have an incentive to not provide labor to maintain the system if they do not receive water. These interdependent incentives may induce a cooperative outcome under favorable conditions. However, how robust is this system of interdependent incentives in the presence of environmental variability that generates uncertainty about water availability either through variation in the water supply itself or through shocks to infrastructure? This paper reports on results from laboratory experiments designed to address this question.
\end{abstract}

\section{Keywords:}




\title{
Environmental variability and collective action: Experimental insights from an irrigation game
}

\author{
John. M. Anderies* \\ Marco A. Janssen ${ }^{\dagger}$ \\ Allen Lee \\ Hannah Wasserman
}

June 20, 2012

\begin{abstract}
Studies of collective action in commons dilemmas in social-ecological systems typically focus on scenarios in which actors all share symmetric (or similar) positions in relation to the common-pool resource. Many common social-ecological systems do not meet these criteria, most notably, irrigation systems. Participants in irrigation systems must solve two related collective action problems: 1) the provisioning of physical infrastructure necessary to utilize the resource (water), and 2) the asymmetric common-pool resource dilemma where the relative positions of "head-enders" and "tail-enders" generate asymmetric access to the resource itself (water). In times of scarcity, head-enders have an incentive to not share water with tail-enders. Likewise, tail-enders have an incentive to not provide labor to maintain the system if they do not receive water. These interdependent incentives may induce a cooperative outcome under favorable conditions. However, how robust is this system of interdependent incentives in the presence of environmental variability that generates uncertainty about water availability either through variation in the water supply itself or through shocks to infrastructure? This paper reports on results from laboratory experiments designed to address this question.
\end{abstract}

\section{Introduction}

There is now a well-developed literature focusing on experimental treatments of commons dilemmas. Although the range of experimental treatments is vast, there are several general, quite robust findings that have emerged from this research. Early work demonstrated that it is possible to construct experimental situations in which non-cooperative equilibria obtained, both in public goods contexts (Isaac et al., 1985, Ledyard, 1995) and common-pool resource contexts (Ostrom et al. 1994). These treatments, however, were very simple and did not allow for communication. Later experimental studies of public goods have shown that participants are willing to invest in public goods and that this investment persists if people can communicate (Isaac and Walker, 1988). Other work has shown that when participants are allowed to talk about the experiment faceto-face and under a non-binding setting of open talk (cheap talk), groups can move toward the cooperative equilibrium (see Ostrom and Walker 1991; Sally 1995; Balliet, 2010; Ahn et al., 2010). Such minor modifications of experiments (the addition of communication) are examples of changes in "micro-situational" variables that significantly change outcomes. Thus, although the experimental results mentioned above are quite robust to changes in player populations, they may be considerably less robust to minor changes in context.

Recent experimental work has become more focused on the role of micro-situational variables in the context of common-pool resource dilemmas (see Anderies et al., 2011 for an overview of this work). Examples of micro-situational variables include group size, communication, heterogeneity among participants, reputation, environmental variability, and time horizons. Among these, heterogeneity among participants is especially important in resource management situations. Specifically, biophysical context generates a particular type of

\footnotetext{
*School of Human Evolution and Social Change and School of Sustainability, Arizona State University. E-mail: m.anderies@asu.edu. Address: PO Box 873211, Tempe, AZ 85287-3211

${ }^{\dagger}$ School of Human Evolution and Social Change, Arizona State University. E-mail: m.janssen@asu.edu

${ }^{\ddagger}$ School of Human Evolution and Social Change, Arizona State University. E-mail: allee@ asu.edu
} 
heterogeneity: asymmetric resource access. Irrigation systems are archetypal examples of commons dilemmas involving asymmetric resource access. Because of the difficulty of the coordination problems they face, it has often been assumed that irrigation systems require a central authority to solve coordination problems (Hunt, 1988; Wittfogel, 1957). However, many examples of complex irrigation systems exist that evolved without central coordination (Lansing, 1991; Ostrom, 1992). In fact, irrigation systems are exemplars of success in collective action (Ostrom, 1992). Their success may, in fact, depend critically on micro-situational variables that induce cooperation when it might not otherwise emerge. Specifically, participants in irrigation systems are often able to overcome asymmetric social dilemmas because of a subtle interdependency between tail-enders' and head-enders' capacity to influence collective action problems related to the maintenance of the irrigation system and allocation of water, respectively (Ostrom and Gardner, 1993).

Recent work has provided experimental evidence that participants are able to overcome asymmetric social dilemmas that mimic the conditions farmers face in real, small scale irrigation systems (Janssen et al. 2011a +2012b). The capacity of small-scale irrigation communities, which encompass $90 \%$ of farms worldwide and support the majority of the world's poorest people (McIntyre et al. 2009), to successfully solve collective action problems is especially important. These systems face a critical challenge: climate change. Climate change will affect where, when, and how much water is available for all uses (Karl et al. 2009) and will likely lead to a situation in which farmers will face an increased level of uncertainty due to changes in water availability (Doll, 2002). The question thus arises: how sensitive is the capacity of irrigation communities to solve collective action problems to uncertainty? In general, uncertainty is an important micro-situational variable in any decision-making problem and we should expect this to be the case for social dilemmas. Early social dilemma experiments did not include uncertainty but several researchers have recently begun to explore its consequences. In the context of public goods games, it has been shown that uncertainty reduces the level of cooperation (Wit and Wilke, 1998; Gustafson et al. 2000; Au 2004). Likewise, experimental work on symmetric common-pool resource dilemmas provides evidence that uncertainty reduces levels of cooperation (Rapoport et al., 1992, Gustafson et al. 2000). None of these, however, explores the role of uncertainty in the more complex situation involving asymmetric resource access.

This article focuses on this question. Building on previous work regarding an irrigation dilemma, we developed, ran, and analyzed a number of experiments to better understand how the ability of participants to solve collective action problems in an irrigation dilemma are affected by various disturbance regimes. This work adds to previous work in this area in two ways:

1. Although we might expect that higher levels of uncertainty will lead to lower levels of cooperation consistent with previous findings (Wit and Wilke, 1998; Gustafson et al. 2000; Au 2004), this cannot be taken for granted. Given the asymmetric nature of the problem, uncertainty about future shocks to headgate infrastructure may actually induce head-enders to be more cooperative than they would otherwise be. That is, we wish to explore how two micro-situational variables (uncertainty and heterogeneity among users) interact.

2. By using a quiz to test the level of understanding of the participants and an exit survey to gather additional demographic information, we can explore how aspects group composition affect the capacity of groups to solve collective action dilemmas.

This work builds on previous treatments with the same biophysical context, allowing us to systematically add of layers of complexity (in terms of the micro-situational variables we manipulate) in the experimental context. We are, of course, well aware of the experimental challenges associated with additional complexity. However, if we are to move beyond very general, simple observations about human behavior in commons dilemmas, we must meet these challenges and endeavor to make experimental outcomes more relevant to real-world policy. This is especially true given the changes human social groups will face in the next few decades.

We now turn our attention to a discussion of the experimental design used in this study. This is followed by a theoretical analysis of optimal strategies to which we then compare the experimental results. We conduct four treatments consisting of a $2 \times 2$ matrix of different types of shocks (shocks to infrastructure and shocks to water supply) and different levels of variability that result from those shocks (high and low). Although the treatments all involve situations in which the amount of water received by farmers varies (whether due to a washout of the head gate or low river flows), the potential responses of the players to these situations are quite different. 


\section{Experimental design}

The experiment takes the form of a 5 player game. The players occupy different positions, A, B, C, D and $\mathrm{E}$, related to their position along the irrigation canal ( $\mathrm{A}=$ upstream, $\mathrm{E}=$ downstream). Each player's view of the game (dashboard) is shown in Figure 1. The player's position is indicated in green and the other players' positions are indicated in yellow. The entire experimental treatment consists of 20 rounds. Each round consists of three stages. In the first stage, participants are allowed to communicate via text messages in a chat room for 40 seconds. In stage 2, participants must make a decision concerning how much to invest in public infrastructure (e.g. canals and water diversion mechanisms). In stage 3, players make decisions regarding opening and closing their irrigation gates over a 50 -second period as they attempt to grow a crop. For example in Figure 1, player C's gate is open, and all other players' gates are closed. There are several other pieces of information shown on the dashboard, the meaning of which will become clear shortly.

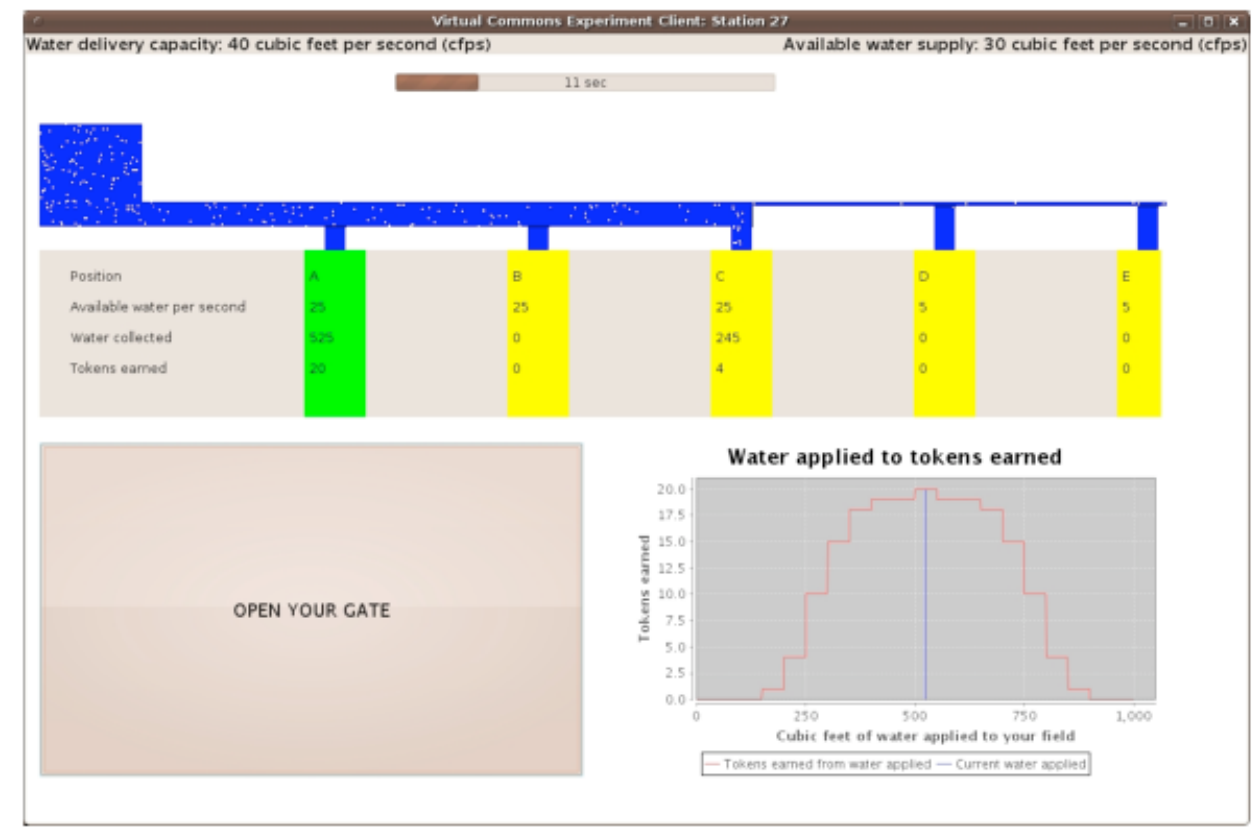

Figure 1: Screen shot of the experiment. 5 participants located in A, B, C, D and E need to make decisions whether to open or close their gate. The water is coming from the left of the screen.

Stage 1 is straightforward. Participants are allowed to discuss anything they wish with the usual caveats (e.g. proper language, no threats, and no promises of side payments). As we will see later, most of the discussion revolves around how much to invest and coordination schemes to open and close gates. Stage 2 requires a more detailed explanation. To aid in ease of interpretation by the players, the "stock" of public infrastructure is measured as a percentage of an arbitrary benchmark value perceived as "excellent working order" (e.g. is capable of reliably delivering $100 \%$ of a benchmark water volume, etc.) The production of public infrastructure depends linearly on the total investment by the group: each token invested increases the infrastructure stock by one unit (note, however, that the productivity of infrastructure depends non-linearly on the infrastructure stock - see below). In each round, players receive 10 tokens, each worth $\$ 0.05$, which can be used for investment. We refer to the total group investment in round $t$ as $\operatorname{INV}(t)$. After each round, the infrastructure depreciates by a constant amount $\operatorname{DEC}(t)$ (canals must be cleaned and diversion and headgate structures must be repaired each year). Thus, the infrastructure stock in the next round, $\operatorname{IS}(t+1)$ is given by

$$
\operatorname{IS}(t+1)=\operatorname{IS}(t)-\operatorname{DEC}(t)+\operatorname{INV}(t+1) .
$$

For example, if at the end of round 1 the infrastructure stock is 75 and each player invests 5 tokens in the investment stage in round 2, the stock will be 100 in the crop growing stage in round 2 . Note, although 
the infrastructure stock can go above 100, it does not perform any better in terms of water availability (a community might keep a system in superb condition for other reasons such as a point of pride or to hedge against future uncertainty).

Table 1: Production function of water delivery as a function of infrastructure.

\begin{tabular}{|c|c|}
\hline Infrastructure efficiency (\%) & Water delivery (cfps) \\
\hline$\leq 45$ & 0 \\
\hline $46-51$ & 5 \\
\hline $52-55$ & 10 \\
\hline $56-58$ & 15 \\
\hline $59-61$ & 20 \\
\hline $62-65$ & 25 \\
\hline $66-70$ & 30 \\
\hline $71-80$ & 35 \\
\hline $81-100$ & 40 \\
\hline
\end{tabular}

Next we relate the level of public infrastructure to the output it generates: the rate of water volume delivery. As with any infrastructure that can be meaningfully called public, water delivery rate versus infrastructure stock exhibits a non-linear s-shaped relationship. Below a certain threshold, infrastructure generates no output. Once this threshold is crossed, additional investment generates increasing returns to scale. Eventually additional investment generates diminishing marginal returns. In the experiments, we have chosen a scaling that that makes it impossible for one person to create sufficient public infrastructure to deliver water without the help of others. For example, a canal with no headgate delivers no water and constructing a headgate for an irrigation system requires a sufficiently large group of people working together at the same time. Hence cooperation is required to generate a level of the public infrastructure that generates a positive return on investment.

The level of water delivery as a function of infrastructure stock is shown in Table 1. The maximum supply of water is 30 cubic feet per second in the default case. In stage 2 of each round players are shown Table 1. They are reminded what the infrastructure level in the previous round was, and are told that it has decreased by the amount $\operatorname{DEC}(t-1)$. They are then asked to make their investment decision. For example if the infrastructure level in the previous round was 75 and $\operatorname{DEC}(t-1)$ was 25 , then the players are told that the infrastructure level at the beginning of round $t$ is 50. Suppose that after stage 1 (communication) each player invests 7 tokens in stage 2 (investment) for a total of 35. Then the infrastructure level at the beginning of stage 3 (crop growing) of round $t$ is $50+35=85$. Based on Table 1 , the system will be capable of delivering a maximum of $40 \mathrm{cfps}$ during stage 3 . After participants have made their investment decision they are shown a screen that summarizes this information for them, i.e. how much each of the participants invested, the level of infrastructure efficiency, the water delivery capacity, and the supply of water to the irrigation system.

In stage 3, the players are presented with the dashboard shown in Figure 1. Stage 3 constitutes a period of 50 seconds during which participants can open their gate to divert water to their field and grow a crop. Participants are shown the water delivery capacity (top left), how much water is available in the river (top right), and how much time is left in the round (top center). Participants see water flowing (movement of white dots to simulate water flow), and their gates opening and closing in real time. The real-time interaction has been purposely chosen to include the need for real-time coordination in order to solve the asymmetric commons problem. That is, the players much execute the strategy (if any) they worked out in the chat session in stage 1 of the round. As players open their gates, they accumulate water in their fields. Table 2 shows the earnings generated by a crop as a function of the total water delivered to the participants' fields. If less than 150 cubic feet of water is diverted to their field, the participant earns no tokens. The maximum number of tokens is earned when a total of 500 to 549 cubic feet of water is delivered to a field. Applying more than $549 \mathrm{cf}$ is detrimental to crop production (water logging) and the earnings go down accordingly.

The maximum capacity of each player's a gate is 25 cubic feet per second. If a participant opens his/her gate and 25 cubic feet water per second is available in the main canal, it takes 20 seconds to reach the maximum earnings possible. With 5 participants attempting to maximize their earnings, there is a demand 
Table 2: Earnings resulting from amount of water applied to your field.

\begin{tabular}{|c|c|}
\hline Water units received (cf) & Tokens earned \\
\hline$<150$ & 0 \\
\hline $150-199$ & 1 \\
\hline $200-249$ & 4 \\
\hline $250-299$ & 10 \\
\hline $300-349$ & 15 \\
\hline $350-399$ & 18 \\
\hline $400-499$ & 19 \\
\hline $500-549$ & 20 \\
\hline $550-649$ & 19 \\
\hline $650-699$ & 18 \\
\hline $700-749$ & 15 \\
\hline $750-799$ & 10 \\
\hline $800-849$ & 4 \\
\hline $850-899$ & 1 \\
\hline$>899$ & 0 \\
\hline
\end{tabular}

of $5 \times 500=2500$ cubic feet of water. Since the maximum supply of water is $30 \mathrm{cf} / \mathrm{s} \times 50 \mathrm{~s}=1500 \mathrm{cf}$ of water, there is a situation of resource scarcity. If participants stop at $300 \mathrm{cf}$, each can generate earnings of 15 tokens. However, if the upstream participants who have first access to water maximize their earnings, the two downstream participants will not receive enough water to generate any earnings from growing a crop. For example, A could open her gate for the first 20 seconds, B for the first 36 seconds, and C, D, and E for the entire period, generating earnings of 20 (500 cf water) tokens each for A and B, 19 (430 cf water) for C, 0 (70 cf water) for $\mathrm{D}$, and 0 ( 0 cf water) for $\mathrm{E}$. This payoff structure sets up our asymmetric commons dilemma.

The group starts in round 1 with a public infrastructure stock of 75 (75\% efficiency), and DEC is 25 for the first 10 rounds of the experiment. We can calculate the Nash and social equilibria (see Appendix) for this experimental design by assuming that participants have zero reaction time and attempt to maximize their number of tokens. In the first round there is no need to invest in the public infrastructure since the delivery capacity $(35 \mathrm{cf} / \mathrm{s})$ is already higher than the supply $(30 \mathrm{cf} / \mathrm{s})$ of water. In a cooperative strategy, participants will keep the infrastructure stock at 66 (delivery capacity $=30 \mathrm{cf} / \mathrm{s}$ ) and invest 25 tokens every round in the infrastructure to maintain it at that level. One of the possible cooperative strategies is to have four participants, A-D, investing six tokens, and one participant, E, only one token. If the participants coordinate their gates, growing a crop can generate 15 tokens for participants A to D and 10 tokens for E. Hence a cooperative strategy can lead to an outcome in which each participant earns 19 per round.

In a non-cooperative setting, we assume that if there is a positive water delivery capacity (infrastructure stock is above 45) and a participant has not reached 500 cubic feet of water, the participant will keep their gate open. Participants will only invest in the public infrastructure if they can rely on a positive return on investment, assuming upstream participants will act as selfish, rational agents. Participants A, B and C will invest modest levels in round 2 to reach the infrastructure level of 66 . In round 3 only participant A will invest. After round 3 the infrastructure will have deteriorated to a level that does not support water delivery. The cooperative strategy leads to 978 tokens for the group in 10 rounds, and the non-cooperative strategy leads to 575 tokens for the group in 10 rounds.

Now we introduce the crucial element for this experiment. After round 10 we introduce variability in the infrastructure dynamics and water supply (Table 3). We distinguish between four potential real-world situations. The first treatment (I-LV) is to vary the decline in infrastructure, DEC. Instead of being a predictable 25 it will be between 15 and 35 (e.g. headgate damage during high flow periods). As before, at the start of the round participants are informed how much the infrastructure has declined and can make the appropriate investment decisions (Figure 2 A solid squares). In the second treatment (I-HV) the variability is increased by varying DEC between 10 and 80 . This means that there are large reductions of the infrastructure during 

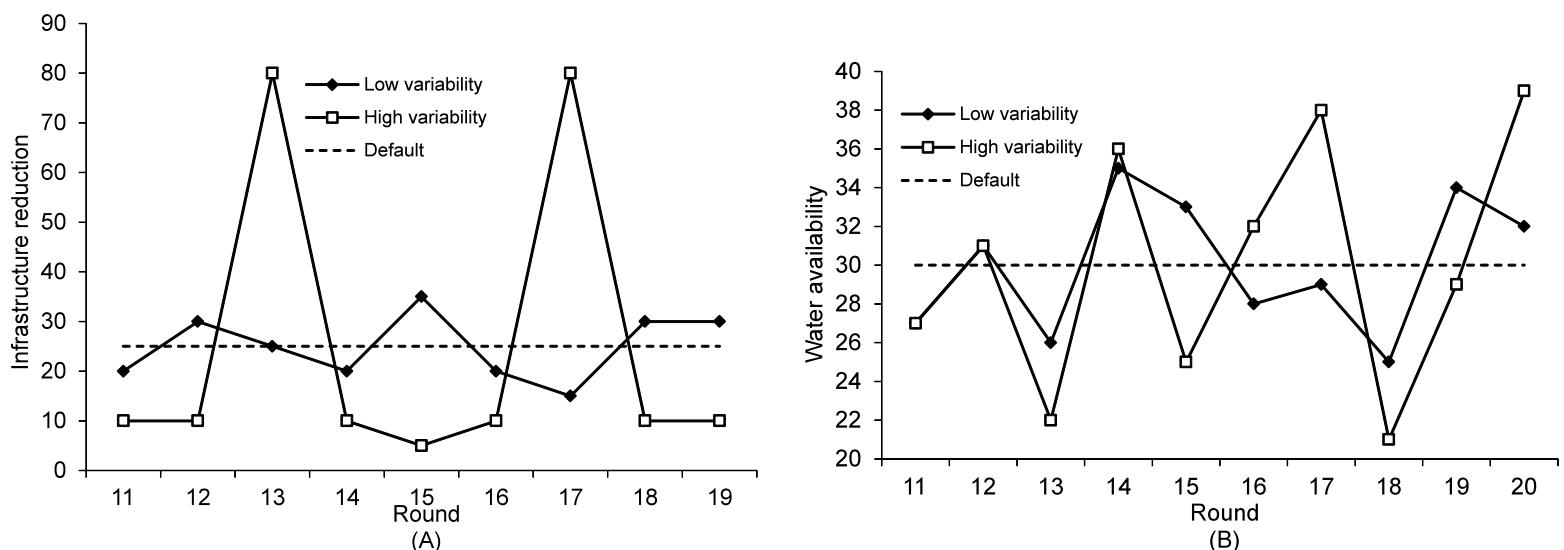

(B)

Figure 2: A: Values of infrastructure decline after the round. B: of the water availability over the rounds.

two rounds (Figure 2 A open squares).

In the third treatment (W-LV) the water supply varies between 25 and $35 \mathrm{cp} / \mathrm{s}$ (e.g. inter-annual variation in water supply) as shown in Figure 2 B (solid squares). Participants do not know the water supply available when they make their infrastructure decision (canals must be cleaned and repaired before the growing season). In the forth treatment (W-HV) there is higher variability in the water supply which varies between 20 and 40 $\mathrm{cp} / \mathrm{s}$ (Figure $2 \mathrm{~B}$, open squares).

Table 3: Experimental design, where $I$ stands for infrastructure, $W$ for water supply, $L V$ for low variability and $H V$ for high variability.

\begin{tabular}{|c|c|c|c|}
\hline Label & Infrastructure decline (\%) & Water supply $(\mathrm{cp} / \mathrm{s})$ & Number of groups \\
\hline I-LV & $15-35$ & 30 & 5 \\
\hline I-HV & $10-80$ & 30 & 6 \\
\hline W-LV & 25 & $25-35$ & 5 \\
\hline W-HV & 25 & $20-40$ & 5 \\
\hline
\end{tabular}

\section{Results}

The experiments were performed in February 2010 at Arizona State University. The participants were recruited from a database of undergraduate students who had indicated that they were willing to take part in experiments with human subjects. This database consists of students from all majors and invitations were sent out to a random sample of the whole population when an experiment was scheduled. Based on exit surveys, of the 105 persons that participated in the experiments reported in this paper, $49 \%$ were female and the average age was 19.4 years. Average earnings were $\$ 21.66$, including a show up bonus of $\$ 5$ plus payments for their play (made in private) for experiments with an average duration of 70 minutes. The individual minimum and maximum earnings were $\$ 12.85$ and $\$ 26.55$, respectively.

Figure 3 shows the average investment levels in the infrastructure across the 21 groups for the four different treatments. For the first 10 rounds we see that the groups, on average, converge to an investment level of about 25 tokens per round. This is just enough to overcome the 25-unit decline each round and to maintain the infrastructure at a constant level. In rounds 11-20, when variability is introduced, the investment levels become more variable. This increased variability is seen both in the treatments with fluctuating infrastructure decline and in the treatments with variability in water supply. The infrastructure level, on average, converges to about 70 in the first 10 rounds (Figure 4 A), just above the socially optimal level of 66. In rounds 11- 20 the 


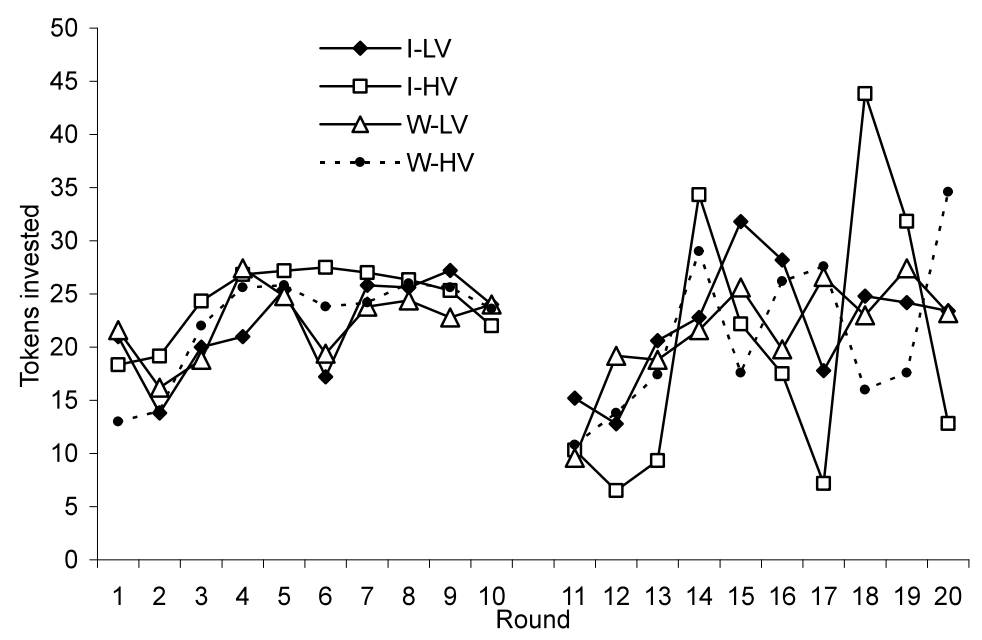

Figure 3: The average investment levels of groups in the four different treatments.

infrastructure level fluctuates between 40 and 80 . Likewise, as a result of the shocks to the infrastructure and water supply the average group earning levels in rounds 11-20 are more variable when compared to rounds 1-10 (Figure 4 B).

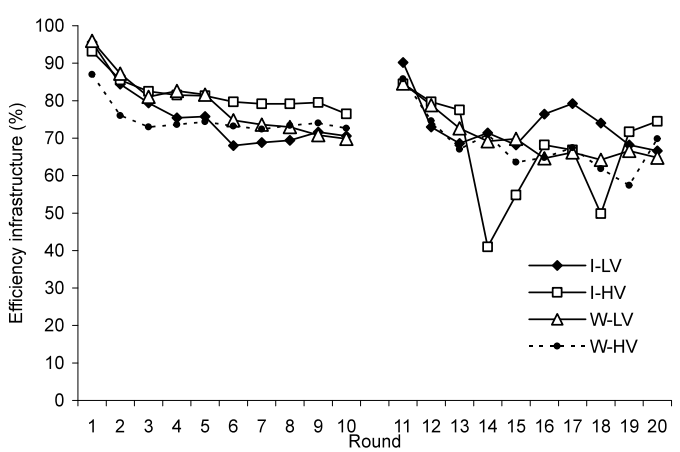

A

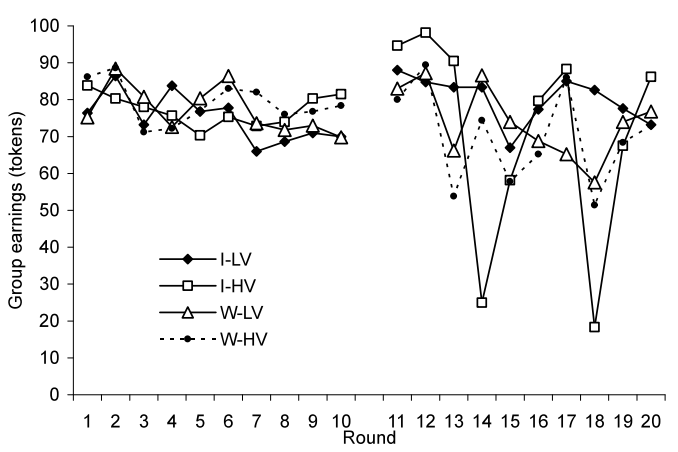

B

Figure 4: A: The average infrastructure efficiency levels of groups in the four different treatments. B: The average group earnings in the four different treatments.

These average statistics for group performance highlight basic patterns in this asymmetric commons dilemma. Namely, performance in the first ten rounds with no uncertainty suggests that groups can cooperate to some extent in this rather complex commons dilemma. Of course, many factors influence the relative performance of groups and several of these are discussed in detail in Janssen et al. (2011). One key element is the willingness of participants to tolerate inequity. The question we are interested in here is the difference between the first 10 rounds with no uncertainty and the second 10 with uncertainty.

Figure 5 shows the investment levels (A) and tokens collected by growing crops (B) over the first 10 and second 10 rounds by position. The main point is that the participants in position $\mathrm{D}$ and $\mathrm{E}$ invest less and generate less from growing crops. Using the two tailed Mann-Whitney test on the average number of tokens invested by the participants over 10 rounds we find that the difference between the first three positions and the last two are statistically significant ( $\mathrm{p}$-value $<0.1$ ). This is also true for the number of tokens earned from growing crops. The differences might be caused by reductions in investment by the downstream participants as a consequence of lower earnings from growing crops. We will investigate this further below. Despite the lower investment levels, the total level of earnings for the last two positions is significantly lower than the first three positions. That is, lower investment levels do not offset the reduced income from receiving less 
water in positions $\mathrm{D}$ and $\mathrm{E}$.

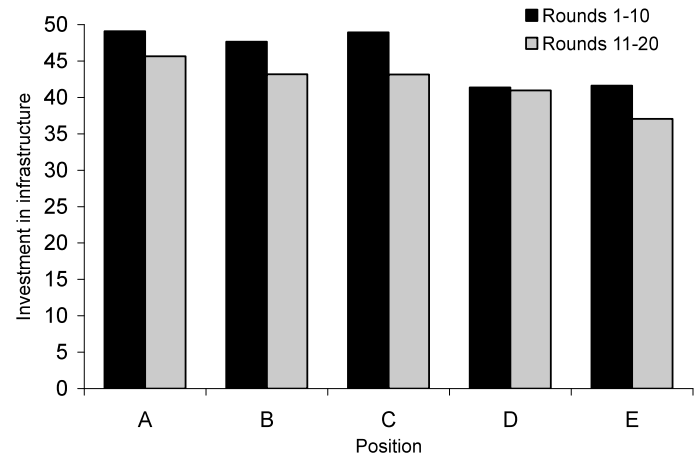

A

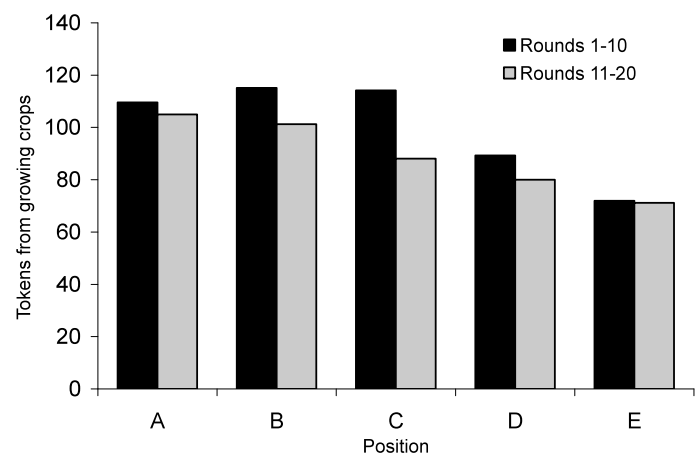

B

Figure 5: The average total level of investments in infrastructure (A) and earned tokens (B) from growing crops per position.

How do uncertainty and variation affect investment and earnings patterns? In three of the four treatments, there is a significant difference between average earnings per round in the first 10 and second 10 rounds (Table 4). The earnings decline significantly in the treatment with high variability of water supply (WHV) and high variability of infrastructure decline (I-HV). For low levels of variability there is no significant decline of earnings. In fact, there is a significant increase in earnings for the treatment with low variability of infrastructure decline (I-LV). The remainder of this section focuses on uncovering factors that may explain these different effects.

Table 4: Average earnings per round. Significance tested on average group earnings using the Wilcoxon Matched Pairs Signed-Ranks Test

\begin{tabular}{|l|c|c|c|c|c|c|c|}
\hline \multirow{2}{*}{ Treatment } & \multicolumn{3}{|c|}{ Rounds 1-10 } & \multicolumn{3}{c|}{ Rounds 11-20 } & Wilcoxon Matched-Pairs Signed- \\
\cline { 2 - 8 } & Nash & S.O. & Actual & Nash & S.O. & Actual & Ranks Test Significance Level \\
\hline I-LV & 57.5 & 97.8 & 75.0 & 66.7 & 98.4 & 80.2 & $\mathbf{0 . 0 5}$ \\
\hline I-HV & 57.5 & 97.8 & 77.2 & 66.7 & 89.7 & 70.7 & $\mathbf{0 . 0 5}$ \\
\hline W-LV & 57.5 & 97.8 & 77.2 & 60.1 & 93.9 & 73.9 & - \\
\hline W-HV & 57.5 & 97.8 & 79.1 & 60.1 & 91.3 & 69.9 & $\mathbf{0 . 0 5}$ \\
\hline
\end{tabular}

Uncertainty generated by variation in water supply and infrastructure decline likely complicates the challenges irrigators face. We would thus expect that a good understanding of how the system functions would become more an important determinant for success in the presence of uncertainty. The statistics in Table 5 show that when variability is added, a higher percentage of correct answers on the quiz by the group members correlates with higher earnings in rounds 11-20 (with variability) but has no significant effect on performance in rounds 1-10 (no variability). This suggests that in the presence of variability and uncertainty, a better understanding of the dilemma situation becomes more important for the capacity of a group to solve this collective action problem.

Table 5 also shows that within-group inequality of earnings from growing crops correlates with lower earnings of the group during the first 10 rounds. This is not surprising since a less equal spread of the irrigation water would lead to lower crop returns. What is more interesting is the effect of inequality in rounds 11-20. A higher level of inequality of earnings during the irrigation phase in rounds 1-10 correlates with lower earnings in rounds 11-20. On the other hand, the relationship between inequality in earnings from crop harvesting in rounds 11-20 and earnings in rounds 11-20 is not significant. Notably, the opposite is true for equality in investment. This is suggestive of some interesting patterns regarding the interaction of micro-situational variables. First, inequality in earnings can affect the long-term dynamics of the group. 
Table 5: Regression results of earnings of groups over 10 rounds. Standard deviations are shown in brackets.

\begin{tabular}{|l|l|l|}
\hline \multicolumn{1}{|c|}{ Factor } & \multicolumn{2}{c|}{ Coefficient } \\
\hline & Rounds 1-10 & Rounds $11-20$ \\
\hline Constant & $\mathbf{8 4 . 5 8 7} * *(\mathbf{4 . 8 8 9})$ & $\mathbf{6 3 . 4 5 6}^{* * *}(\mathbf{6 . 8 1 2})$ \\
\hline Fraction male & $-2.656(3.777)$ & $4.115(5.139)$ \\
\hline Fraction econ majors & $5.541(5.233)$ & $-0.217(8.049)$ \\
\hline $\begin{array}{l}\text { Fraction quiz questions } \\
\text { correct }\end{array}$ & $2.599(7.959)$ & $\mathbf{3 4 . 2 3 3} * * *(\mathbf{1 1 . 8 5 7})$ \\
\hline I-LV & & $\mathbf{1 1 . 2 5 1} * * * \mathbf{4 . 1 1 4})$ \\
\hline I-HV & & $-5.680(3.998)$ \\
\hline W-LV & & $5.916(5.503)$ \\
\hline Gini invest rounds 1-10 & $-14.079(12.969)$ & $18.260(19.179)$ \\
\hline Gini collect rounds 1-10 & $\mathbf{- 2 8 . 5 0 4 * * ( 1 2 . 9 6 3 )}$ & $\mathbf{- 5 9 . 7 5 4 * * * ( 2 1 . 7 4 3 )}$ \\
\hline Gini invest rounds 11-20 & & $\mathbf{- 2 3 . 8 4 6 * ( 1 4 . 1 4 5 )}$ \\
\hline Gini collect rounds 11-20 & & $26.373(18.003)$ \\
\hline & & \\
\hline N & 21 & 21 \\
\hline Log likelihood & 61.428 & 64.999 \\
\hline Walt test & $20.96(\mathrm{p}<0.001)$ & $75.94(\mathrm{p}<0.001)$ \\
\hline
\end{tabular}

Groups who experienced inequality in earnings during a period without environmental uncertainty (rounds 1-10) experienced a larger decline in earnings during a subsequent period (rounds 11-20) with uncertainty. Second, in a stable environment without uncertainty, inequality of investment is less important than inequality of earnings. The opposite is true with uncertainty.

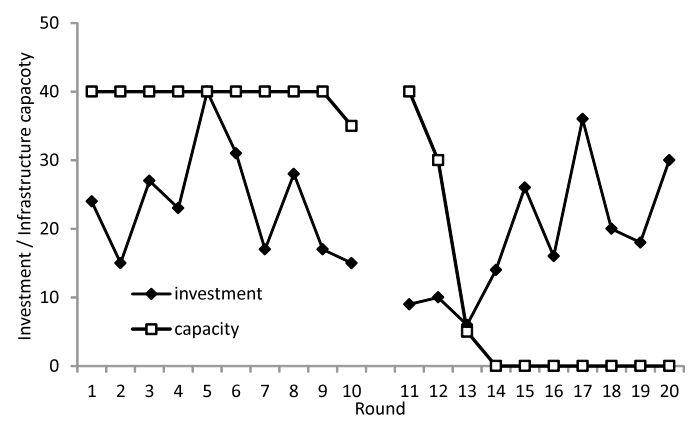

(A)

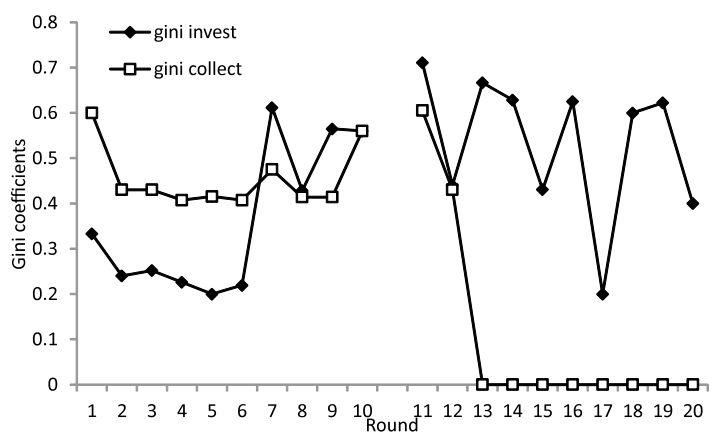

(B)

Figure 6: Group level statistics of the group with the lowest earnings in rounds 11-20.

These statistical results suggest that micro-situational variables interact: different types of inequality may be more or less important in different uncertainty contexts. To explore possible mechanisms that generate variation across cases we can utilize details from some individual groups. We begin with a comparison of the groups with the lowest and highest earnings in rounds 11-20. Both groups participated in the low variability in water availability (W-LV) treatment. Figure 6 shows summary statistics by round for the group with the lowest earnings in rounds 11-20. The group did not invest enough to maintain the irrigation infrastructure. After 4 rounds of low investment, the efficiency dropped well below 45 in round 14 and water delivery capacity fell to zero. Despite an increase in investment in subsequent rounds, it was never sufficient to push the efficiency back above $45 \%$. What might have been the cause of this rapid decline in investment?

In rounds 1-10 we see considerable inequality in investment and earnings from growing crops. Investment 
started to fall below the level needed to overcome the infrastructure decay in rounds 9 and 10 . The player in position $\mathrm{D}$ never invested in the public infrastructure and the player in position $\mathrm{E}$ did not invest in rounds 7 , 9 and 10. Players in positions D and E did not earn a significant number of tokens during the crop-growing stage. The player in position D participated in the communication stage and stated that (s)he would be satisfied with earning 50 cents each round by not investing and not using any water. Since upstream participants did not leave water for participant $\mathrm{E}$, (s)he expressed increasing dissatisfaction as rounds progressed. When the infrastructure collapsed, the group could not recover without contributions from the player in position D.

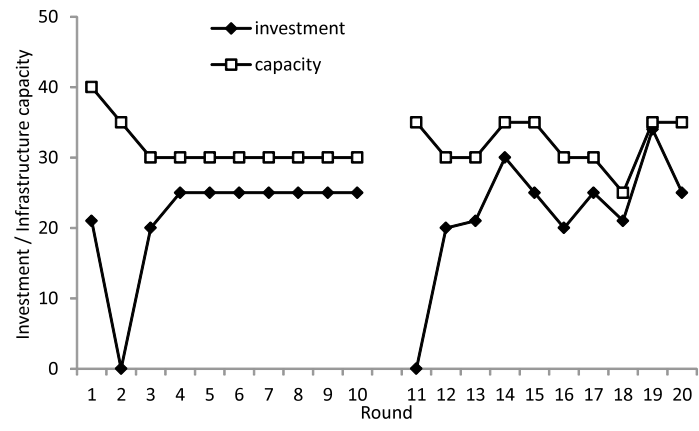

(A)

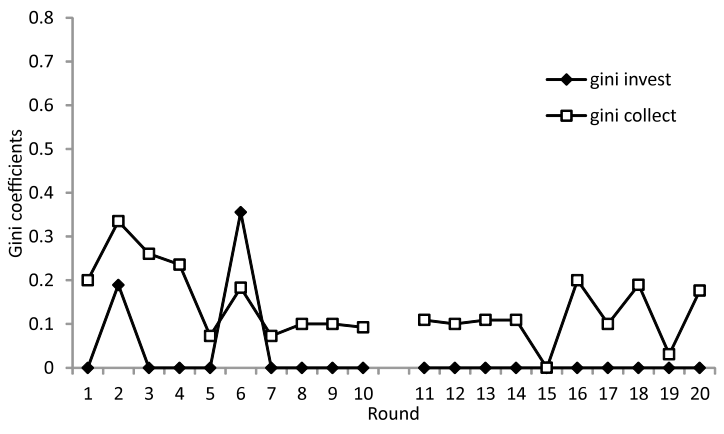

(B)

Figure 7: Group level statistics of the group with the highest earnings in rounds 11-20.

Figure 7 shows the same data for the best performing group. In rounds 1-10, group investment quickly converges to the level required to overcome the per-round decay of infrastructure. The investment levels in rounds 11-20 were more variable, but were still around 25 tokens each round. The number of tokens collected during irrigation stages was relatively low and the gini coefficient was zero in most rounds. This shows that the group had achieved a high level of equity regarding both contributions to public infrastructure and extraction from the common-pool resource. In the communication among the participants, it is clear that they quickly converged to investing 5 tokens each round and to an understanding that downstream participants should also earn tokens during the irrigation stage of each round.

In the I-HV treatment, the groups experience at least one round in which the reduction in infrastructure stock is sufficiently large to almost cause total collapse of the infrastructure (e.g. headgate washout). Such events will put the cooperative capacity of the group to the test. Again, we look at the groups who performed best and worst in this treatment. Figure 8 summarizes the per-round performance for the latter. In fact, for this group there is almost no investment in infrastructure after round 10. This leads to a collapse of the infrastructure in round 14. Notice that the investments initially were above the replacement level in rounds $2-8$, and then dropped below replacement level in rounds 9 and 10. Based on their communication, the group was learning what they thought was the best strategy leading to the highest earnings. They concluded in rounds 11 and 12 that not investing at all led to the best outcome, not realizing it would lead to collapse of the infrastructure. Because they let the infrastructure slip in rounds 11-13, the group could never recover from the large shock in round 14. For this group, it seems that lack of understanding of the system was a more important driver for system performance than were equity concerns (note, this groups average quiz score was $27 \%$ compared to $55 \%$ for groups in this treatment).

Analogous statistics for the best performing group in the I-HV treatment are shown in Figure 9. The group invested about 25 tokens in rounds 1-10 and kept the infrastructure at 40 (a slight overinvestment in infrastructure, in fact). In rounds 11-20 the investment levels responded nicely to the need for investment to maintain the infrastructure (compare to Figure $2 \mathrm{~A}$ ). The communication among participants shows a concern for equality both in investment levels and water extraction during the irrigation rounds. It is also interesting to note that this group's quiz score was $62 \%$; higher than the average for groups in this treatment, but not the highest. 

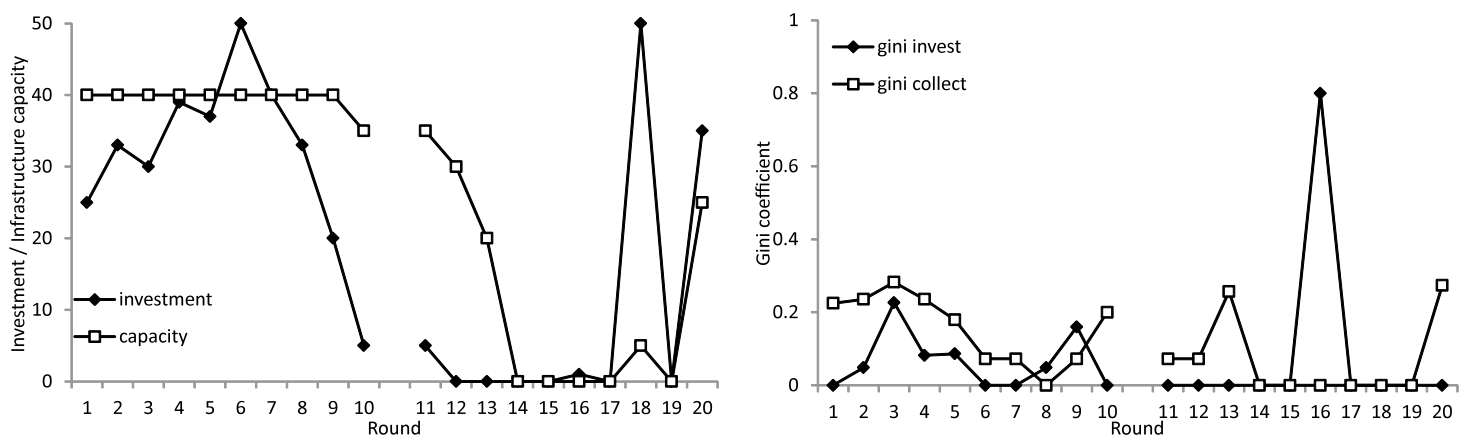

A

B

Figure 8: Group statistics with the lowest earnings in I-HV

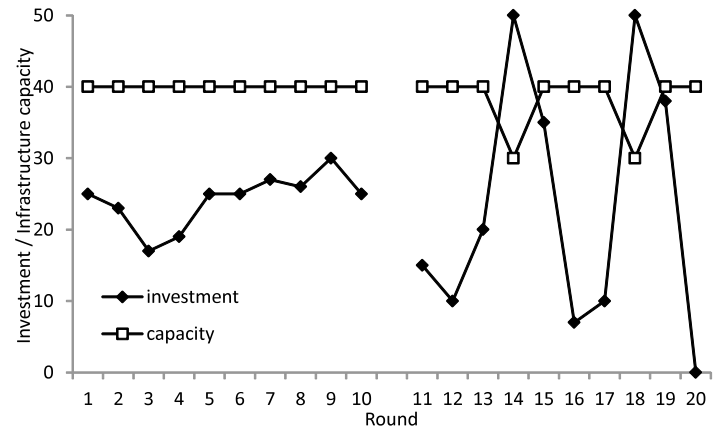

A

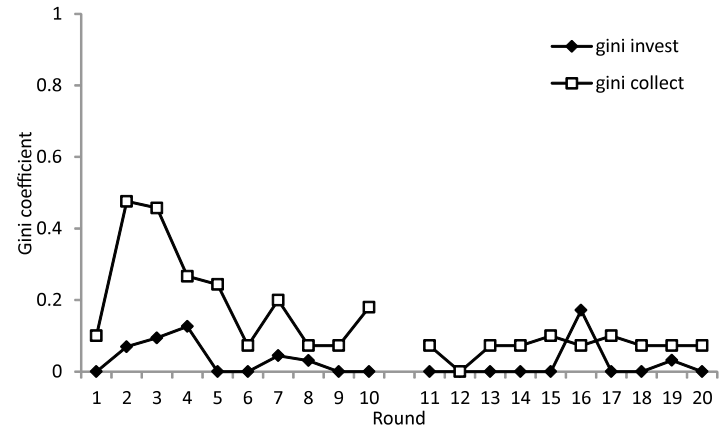

B

Figure 9: Group statistics with the highest earnings in I-HV

\section{Conclusions}

Many small-scale irrigation systems around the world depend on the success of irrigators to solve the twostage collective action problem contained in the experimental treatments that form the basis of this paper. These systems feed and provide livelihoods for a large proportion of the world's population. A critical question raised in the introduction is how sensitive such systems are to changes in the biophysical context in which they operate. Put in more practical terms, this question boils down to what is the capacity of these systems to continue to function in the face of climate change.

To address this question, we must understand how vulnerabilities emerge in these systems. Anderies and Janssen have emphasized the role of fundamental properties of feedback systems in regard to the capacity of social-ecological systems to cope with change: robustness vulnerability trade-offs (Anderies and Janssen, 2011, Janssen et al., 2007). As systems become highly tuned to the biophysical context in which they operate, they can develop robustness properties that are highly optimized for particular classes of disturbances and particular structural properties associated with that biophysical context. In so doing, new, hidden vulnerabilities may emerge. It is possible to explore robustness-vulnerability trade-offs in broad terms at the system level with dynamic mathematical models informed by case studies (Cifdaloz et al., 2010). However, to really understand how microsituational variables impact system performance and vulnerability, we must probe the details of human decision making more deeply. The work reported here is an effort in this direction.

Our experiments show that high variability of water supply or infrastructure decay leads to significantly lower levels of earnings. This suggests that systems facing changing disturbance regimes to which they have not yet adapted (e.g. a shift from rounds 1-10 to 11-20) will likely suffer declines in performance. Having said that, our experiments suggest that a good understanding of system structure may enable communities 
to adapt. A higher number of correct answers to quiz questions on the experimental environment does not correlate with decisions in the first 10 rounds. That is, stable environmental conditions may make systems more robust to poor understanding of system dynamics. On the other hand, in the second 10 rounds, groups with higher average level of correct answers get significantly higher earnings.

Our experiments also illustrate the importance of another microsituational variable: equality. Inequality of water use leads to lower group earnings. One explanation is that inequality of water use is considered to be unfair. Our results show that this is true in general. However, when combined with uncertainty, the experiments suggest that uncertainty and inequality interact. Inequality in earnings is most important in a stable environment. This may be due to the fact that stability enables participants to easily assess equality and attribute it to decisions of other players. In uncertain environments on the other hand, equality in investments is more important. This may be due to the fact that it may be more difficult for participants to attribute inequality in earnings to actions of other players (and invoke some notion of unfairness). They may attribute some of this inequality to a changing environment. Investments, on the other hand, are easily attributed to the decisions of other players. Thus, as long as everyone invests equally, inequality in earnings may be more tolerated. Further, when looking at the lowest performing group in the I-HV treatment, we see that angering even one player can lead to system collapse. In a stable biophysical context, groups may be able to tolerate non-cooperative behavior of a single player. However, with the potential for large shocks, non-cooperative behavior can become catastrophic.

These results are suggestive for our understanding of highly optimized robustness. Over longer time scales, experiences of system collapse may induce upstream players to take more care in promoting equitable distribution of water because they have learned that when times get really tough, the cooperation of everyone is required. However, this would require a certain frequency of occurrence of extreme events to keep the need for maintaining equity fresh in the social memory of the group. That is, the system is robust for a certain frequency of disturbance events. If the frequency of disturbance events decreases, social memory might be lost, and the system may collapse as in our experiments. What is this frequency?

Finally, how do system understanding and perceptions of fairness interact? Can groups with excellent understanding of the system overcome challenges even if participants feel distribution of benefits from cooperation are unfair? On the other hand, is fairness capable of conferring robustness in general even if participants don't understand how the system functions very well? Such questions are critical for understanding how small-scale irrigation systems will cope with global change. Continued carefully designed experiments like the one reported on here should focus on teasing apart these different factors that may impact the dynamic behavior of social-ecological systems.

\section{Acknowledgements}

We dedicate this paper to the memory of Elinor Ostrom whose pioneering work on experimental studies of collective action laid the foundation for our work. We acknowledge financial support for this work from the National Science Foundation, grant numbers SES-0645789, SES-0748632 and BCS-1115054.

\section{References}

Ahn, T., Ostrom, E., and Walker, J. (2010). A common-pool resource experiment with postgraduate subjects from 41 countries. Ecological Economics, 69(12):2624-2633.

Anderies, J. and Janssen, M. (2011). The fragility of robust social-ecological systems. Global Environmental Change, 21(4): 1153-1156.

Anderies, J., Janssen, M., Bousquet, F., Cardenas, J., Castillo, D., Lopez, M., Tobias, R., Vollan, B., and Wutich, A. (2011). The challenge of understanding decisions in experimental studies of common pool resource governance. Ecological Economics 70(9):1571-1579.

$\mathrm{Au}$, W. (2004). Criticality and Environmental Uncertainty in Step-Level Public Goods Dilemmas. Group Dynamics: Theory, Research, and Practice 8:40-61. 
Balliet, D. (2010). Communication and cooperation in social dilemmas: A Meta-Analytic Review, Journal of Conflict Resolution 54(1): 39-57.

Biel, A., T. Gärling (1995). The role of uncertainty in resource dilemmas, Journal of Environmental Psychology 15(3): 221-233.

Cifdaloz, O., Regmi, A., Anderies, J., and Rodriguez, A. (2010). Robustness, vulnerability, and adaptive capacity in small-scale social-ecological systems: The Pumpa irrigation system in nepal. Ecology and Society, 15(3):39.

Doll, P. (2002) Impact of climate change and variability on irrigation requirements: A global perspective, Climatic Change 54(3): 269-293.

Gustafsson, M., A. Biel, and T. Gärling. Egoism Bias in Social Dilemmas with Resource Uncertainty. Group Processes and Intergroup Relations 3:351-65.

Hunt, R.C. (1988). Size and structure of authority in canal irrigation systems. Journal of Anthropological Research 44(4): 335-375

Isaac, R., McCue, K., and Plott, C. (1985). Public goods provision in an experimental environment. Journal of Public Economics 26(1):51-74.

Isaac, R. and Walker, J. (1988). Communication and free-riding behavior: The voluntary contribution mechanism. Economic Inquiry 26(4):585-608.

Janssen, M.A. (2010) Introducing Ecological Dynamics into Common Pool Resource Experiments, Ecology and Society 15(2):7

Janssen, M., Anderies, J., and Ostrom, E. (2007). Robustness of social-ecological systems to spatial and temporal variability. Society and Natural Resources 20(4):307-322.

Janssen, M.A., Anderies, J.M., Joshi, S.R. (2011). Coordination and Cooperation in Asymmetric Commons Dilemmas, Experimental Economics, 14(4):547-566.

Janssen, M.A., Bousquet, F., Cardenas, J.C., Castillo, D., Worrapimphong, K.,( 2012). Field Experiments of Irrigation Dilemmas, Agricultural Systems 109: 65-75

Karl, T. R., J. M. Melillo, and T. C. Peterson, editors. (2009). Global climate change impacts in the United States. Cambridge University Press, Cambridge, UK.

Lansing, J.S. (1991). Priests and Programmers: Technologies of Power in the Engineered Landscape of Bali. Princeton University Press.

McIntyre, B. D., H. R. Herren, J. Wakhungu, and R. T. Watson, editors. (2009). International Assessment of Agricultural Knowledge, Science and Technology for Development (IAASTD): Global Report. IAASTD. online [URL]:http://www.agassessment.org/

Ostrom, E. (1992). Crafting Institutions for Self-Governing Irrigation Systems. ICS Press, San Francisco, CA.

Ostrom, R., Gardner, R. (1993). Copying with Asymmetries in the Commons: Self-Governing Irrigation Systems Can Work. Journal of Economic Perspectives 7(4): 93-112. 
Ostrom, E., Walker, J.M. (1991). Communication in a Commons: Cooperation without External Enforcement. In Research in Political Economy, in Palfrey, T.R. (ed.) Ann Arbor: University of Michigan Press. Pp. 287-322.

Poteete, A.R., Janssen, M.A., Ostrom, E. (2010). Working Together: Multiple Methods in Practice, Collective Action and the Commons, Princeton University Press.

Rapoport, A., Budescu, D., Suleiman, R., and Weg, E. (1992). Social dilemmas with uniformly distributed resources. In Liebrand, W., Messick, D. M., and Wilke, H., editors, Social dilemmas: Theoretical issues and research ?ndings, pages 43-57. Pergamon Press.

Sally, D. (1995). Conservation and Cooperation in Social Dilemmas: A Meta-Analysis of Experiments from 1958 to 1992. Rationality and Society 7:58-92.

Wit, A., and H. Wilke (1998). Public Good Provision under Environmental and Social Uncertainty. European Journal of Social Psychology 28, 249-56.

Wittfogel, K.A. (1957). Oriental Despotism: A Comparative Study of Total Power, Yale University Press, New Haven, CT. 